\title{
The role of social support in the relationship between mental health and posttraumatic stress disorder amongst orthopaedic patients
}

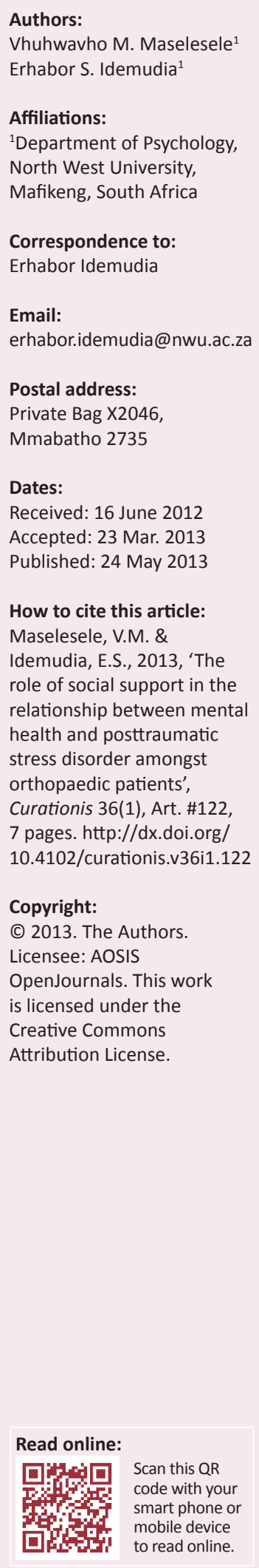

Background: Some life-event experiences such as injuries in car accidents, gun shots and the like, can be life changing and traumatic.

Objectives: The article investigated the relationship between mental health and posttraumatic stress disorder (PTSD) symptoms after orthopaedic trauma, and attempted to understand whether social support moderates the relationship between mental health and PTSD.

Method: A cross-sectional research model was used. Two hundred participants were selected using simple randomisation within a hospital complex in Gauteng, South Africa. The sample consisted of 110 men and 90 women $(\bar{x}=37.8$ years, s.d. $=12.9$ years). Data were collected using the Revised Civilian Mississippi Scale for PTSD, the Multidimensional Scale of Perceived Social Support (MSPSS), and the General Health Questionnaire version 28.

Results: The findings of the study indicated that there is a statistically significant relationship between mental health and PTSD after orthopaedic trauma, and a positive correlation between poor mental health and PTSD $(r=0.52, n=200, p<0.05)$. However, perceived social support did not moderate mental health or PTSD, indicating that perceived social support did not significantly influence mental health or PTSD, (MSPSS $B=0.07, p=0.66$ ). Those with high scores on social support had a lower regression coefficient $(B=0.19)$ for mental health and PTSD than those who reported low social support $(B=0.26)$.

Conclusion: There is a significant relationship between mental health and PTSD of orthopaedic patients, and social support did not moderate the relationship between mental health and PTSD.

\section{Introduction}

Traumatic injuries account for nine per cent of the global mortality and survivors of traumatic injuries face physical, emotional and financial repercussions that can impact their lives and that of their families (Steel et al. 2011:288). Victims of orthopaedic trauma are extremely vulnerable to psychiatric disorders in the months and years following the trauma (Malt 1988, cited in Latchford 2003:2). According to Clay, Newstead and McClure (2010:787), regardless of the severity of injury, orthopaedic trauma is a major cause of personal suffering and of ongoing pain, disability, economic and social costs.

According to the World Health Organization (WHO 2009:3), between 20 million and 50 million non-fatal injuries are estimated to occur annually around the world, and in addition, annual injuries due to violence, motor vehicle accidents, burns, falls or drowning account for $16 \%$ of all disabilities. Globally, more than 1.5 million persons sustain traumatic physical injuries each year (Wong et al. 2011:67). A significant proportion of traumatic injury survivors develop serious mental health problems, such as posttraumatic stress disorder (PTSD), yet few obtain professional mental health care (Wong et al. 2011:68). Furthermore, millions of orthopaedic patients suffer from permanent or temporary disabilities and lose more years of work life than individuals with cancer or heart diseases combined (Steel et al. 2011:288).

Several studies have been conducted on trauma due to interpersonal violence such as domestic violence (Najavits et al. 2004; Jones, Hughes \& Unterstaller 2001), sexual assault (Yehuda 2002) and on the experiences of military veterans (Forbes, Creamer \& Biddle 2001). Despite the few studies (Ehlers, Mayou \& Bryant 1998; Starr et al. 2004) carried out on orthopaedic trauma, there are still knowledge gaps in the area because there are very few studies focusing on how social support will moderate the relationship between mental health and PTSD. Thus this study intends to bridge the knowledge gap by investigating the role of social support on PTSD symptoms and 
mental health amongst patients after orthopaedic injuries. For the purpose of this study, orthopaedic trauma is defined as injuries resulting from traumatic experiences such as car accidents, gunshot wounds, violence and a fall resulting in orthpaedic hospitalisation.

Starr et al. (2004:1115) have noted that despite physical healing, many orthopaedic patients do not go back to work or complain about recurring dreams or flashbacks. Ponsford et al. (2008:1001) found that sufferers of orthopaedic trauma continue to have functional problems, physical and emotional or psychosocial problems long after the injury has healed. For the purpose of this study, poor or impaired mental health is defined as psychological distress as described by the General Health Questionnaire-28 (GHQ-28), with four subscales, namely somatic symptoms, anxiety and insomnia, social dysfunction and depression (Goldberg \& Hillier 1979). It is on the basis of the studies reviewed above that two hypotheses were formulated: that (1) there will be a statistically significant positive relationship between poor or impaired mental health and PTSD amongst orthopaedic patients, and (2) that social support will play a positive role or moderate mental health and PTSD amongst orthopaedic patients.

\section{Aim of the study}

The aim of this study was to empirically determine whether perceived social support as a variable will moderate the relationship between mental health and PTSD.

\section{Objectives}

- To investigate the relationship between mental health and PTSD symptoms after orthopaedic trauma

- To investigate whether social support of patients will moderate their mental health and PTSD.

\section{Significance of the study}

One out of every two patients who have experienced orthopaedic trauma could be experiencing PTSD, which could affect the healing process (Starr et al. 2004:1119). The identification of factors associated with poorer outcomes would provide a basis for the development of guidelines to improve the management and rehabilitation of victims of injury-related orthopaedic trauma, thereby reducing the costs to funding bodies and the healthcare system. Non-fatal injuries come with a high, social, emotional and economic burden on the family concerned as well as society as a whole. This issue should be recognised as a public health problem by policy makers and health planners in South Africa. Therefore, this study will help health workers to pay attention to the patients' psychological status following orthopaedic injuries. It will also assist policy makers to develop intervention programmes that address psychological and social issues. Due to limited resources, it is vital to accurately identify patients who are at risk so that these resources can be effectively and efficiently used for those who need them.

\section{Theoretical background}

The study was conceptualised within Cohen and Wills' stress-buffering hypothesis (Cohen \& Wills 1985:310). The hypothesis states that social support has an indirect and stressreducing effect by buffering the negative consequences of a traumatic event (Cohen \& Wills 1985:312). When stress has been experienced, social support may reduce or moderate the affective reaction to the traumatic event, therefore decreasing the importance of the event and leading to improved coping mechanism (Rees et al. 2010:506).

For the purpose of this study, buffering would mean that the detrimental relationship between orthopaedic trauma and psychological responses (mental health and PTSD) would be less for those patients who have high social support than for those with low social support. Therefore, social support will moderate the positive relationship between mental health and PTSD amongst orthopaedic patients. According to Rees et al. (2010:510), people whose daily activities or normal functioning have been disrupted have reported feelings of depression and frustration.

\section{Post traumatic stress disorder and orthopaedic trauma}

Psychological trauma refers to the impact of an extreme stressor or critical incident on an individual's psychological and biological functioning. Trauma has been defined as a 'morbid condition of the body produced by wound or external violence' (Girolami, Foex \& Little 1999:3).

According to the Diagnostic and Statistical Manual of Mental Disorders IV-TR (DSM-IV-TR, American Psychiatric Association 2000:219), PTSD is characterised by exposure to a traumatic event in which the individual experienced, witnessed or was confronted with an event that involved actual or threatened death or serious injury or a threat to the physical integrity of self or others and that the individual responded to such an event with intense fear and/or helplessness or horror. According to Yehuda (2002:109), traumatic events that usually result in PTSD involve interpersonal violence (being a victim of a violent assault, rape or abuse) or exposure to life threatening accidents (motor vehicle accidents, pedestrian-vehicle accidents), military combat, bombings, natural disasters (earthquakes, floods, etc.), or being diagnosed with a chronic illness. The DSM-IV-TR (2000:220) suggested that those who are traumatised will exhibit a cluster of the following symptoms: one or more symptoms of flashbacks of the event (intrusive phenomena); three or more symptoms of social withdrawal (avoidant behaviour) and two or more symptoms of anxiety (hyper-arousal), and that these symptoms will persist for at least a month and cause significant distress or impairment in social occupational or other important areas of functioning.

Various studies on PTSD and injury have been conducted on people involved in road accidents (Mayou, Ehlers \& Bryant 2002:665; Ongecha-Owuor et al. 2004:362). Chossegros et al. (2011:471) suggested that motor vehicle accidents are a principal cause of PTSD. 
Meta-analytic studies conducted by Brewin et al. (2000) and Ozer (2003) cited in Elwood et al. (2009:88), found that perceived social support was the strongest predictor of PTSD. Brewin et al. (2000, in Elwood et al. 2009:89) found that female gender, lower socioeconomic status, less education, lower intelligence and childhood adversity were weak predictors of PTSD. Several of the studies conducted on PTSD and orthopaedic or physical traumas are on motor vehicle accident (MVA) victims (Rusch 1998; Mayou, Ehlers \& Bryant 2002; Ongecha-Owuor et al. 2004). The prevalence rate of PTSD following MVAs varies widely depending on the methodology and the population that was studied. A study (Blanchard \& Hickling 1997) conducted on PTSD on survivors of MVA using the Clinician Administered PTSD scale found a prevalence rate of 39.2\%. Mayou, Bryant \& Duthie (1993:648) used the Present State Examination (PSE) and the Diagnostic and Statistical Manual of mental disorders IIIR (DSM-IIIR) and found a prevalence rate of $8 \%$ and $11.1 \%$, three and twelve months after the accident. Green $e t$ al. (1993:530) used the Diagnostic Interview Schedule (DIS), the General Health Questionnaire (GHQ) and the DSM-IIIR and found prevalence rates of $8.3 \%$ and $25 \%$, one and eight months after the accident.

Lilly et al. (2009:767) indicated that women suffer from posttraumatic stress disorder more intensely than men. However, men are exposed to more traumatic events than women. Women report PTSD more frequently than men after exposure to a traumatic event.

\section{Mental health and orthopaedic trauma}

According to Corrigall et al. (2007:60), mental health problems have led to an increase in financial costs across the world because of absenteeism, which also leads to decreased productivity. They further stated that the impact of mental health is underestimated in South Africa. Depression and PTSD are associated with loss in wages, use of temporary workers, sick time, an inability to fully function and increased costs (Richmond et al. 2011:327).

A study conducted to predict the future development of depression or PTSD after injury by Richmond et al., (2011:331) suggested that $37 \%-56 \%$ of injured people experience depression and that PTSD is also common after injury, with $10 \%-22 \%$ of people experiencing it. Injured patients are more likely to commit suicide, an extreme indicator of the impact of depression and psychiatric comorbidity.

People with poor mental health are more likely to be unemployed, live in poor conditions and are less likely to have completed school. PTSD can be considered a possible but not inevitable outcome following trauma. Since the 1980s until recently, few studies have examined the development of psychiatric disorders other than PTSD. Yehuda, McFarlane, and Shalev (1998:1305) suggested that exposure to trauma precipitates the development of many different psychiatric disorders that may occur with or without PTSD. Shalev et al. (1998a in Yehuda, McFarlane, \& Shalev 1998:1306) conducted a study on a group of Hadassah emergency room patients immediately after being exposed to a traumatic event, with follow up made four months later. There were 211 participants available for follow up; two-thirds of the sample had no psychiatric disorder four months after exposure. Of the rest of the participants, $17 \%$ met the diagnostic criteria for PTSD, $14 \%$ met the diagnostic criteria for major depression and 15\% met the diagnostic criteria for other anxiety disorders besides PTSD.

For the purpose of this study, mental health was investigated using the GHQ-28 version developed by Goldberg and Hillier (1979) with four subscales: somatic symptoms, anxiety and insomnia, social dysfunction and depression.

In a study of 1048 seriously injured trauma patients, $60 \%$ were found to be depressed at discharge, and 31\% at six month follow up (Holbrook et al. 1998:320). Depression was found to be associated with functional outcomes, as were posttraumatic stress symptoms (Latchford 2003). Based on the literature and theoretical background, it was hypothesised that there will be a statistically significant positive relationship between mental health and PTSD in orthopaedic patients.

\section{Social support and orthopaedic trauma}

Current research suggests that social support has beneficial effects on physical and mental health outcomes, and literature on social support suggests that perceptions of support networks play an important role in determining the degree to which individuals will seek out and use social resources (Clapp \& Beck 2009:237; Bal et al. 2003:3). Social support can be defined as the social interactions and relationships that offer help or attachment and are perceived as loving and caring (Pruitt \& Zoellner 2008:254). Cohen, Gottlieb and Underwood (2000, cited in Ibarra-Rovillard \& Kuiper 2011:343) defined social support as any social relationship that promotes health and wellbeing.

Research has maintained that a positive correlation exists between social support and mental health, irrespective of how the researchers have differentiated social support and how they went about measuring and quantifying it (Tajalli, Sobhi \& Ganbaripanah 2010:100). In a meta-analysis by Brewin et al. (2000, cited in Elwood et al. 2009:88), social support was found to be the strongest predictor, accounting for $40 \%$ of variance in PTSD severity. Predictors of poor mental health after traumatic injury include younger age at the time of the injury, shorter duration between the injury and assessment, higher degree of pain and lower levels of social support. Cohen and Wills (1985:312) indicated that people with spouses, friends and family members who provide psychological and material resources are in better health than those with less social support. As a result, the study hypothesised that social support will moderate mental health and PTSD. 


\section{Study design}

A cross-sectional design was used in the study. Data were collected from 200 patients in a hospital complex, in Gauteng, South Africa. The aim of the present study was to determine empirically whether there would be a relationship between mental health and PTSD and whether perceived social support as a variable will moderate the relationship between mental health and PTSD. Therefore, a multiple regression was conducted using SPSS 20 for the stated hypotheses and by implication zero-order correlation, regression analyses were used with a statistical decision of $p<0.05$.

\section{Participants}

Participants who met the inclusion criteria were randomly selected using a table of random numbers of 'yes' and 'no' from the orthopaedic wards and clinic at Steve Biko Academic Hospital in Pretoria, Gauteng. The sample consisted of 110 men and 90 women $(\bar{x}=37.8$ years, s.d. $=12.9$ years). Sample characteristics showed that there were more men (55\%) exposed to orthopaedic trauma at the time of data collection and that most participants had only matric (43.5\%). Forty-two per cent of the orthopaedic participants were employed on a full-time basis and the main cause of injury was car accidents (44\%). Finally, $42 \%$ of the participants in this study were single. The inclusion criteria for participation in the study were that patients must have had an injury for at least 6 months, were either male or female, were 18 years or older, were willing to participate and must have had physical injuries. The exclusion criteria were patients who were younger than 18 years, those with head injuries and those injured less than six months previously.

\section{Measuring instruments}

The Revised Civilian Mississippi Scale for PTSD (Norris \& Perilla 1996): This is a self-report measure, with thirty items, scored on a 5 -point Likert scale $(1=$ not true, $5=$ extremely true). This scale consists of 10 questions concerning symptoms of avoidance, 8 questions concerning symptoms of intrusion, 7 concerning symptoms of hyper-arousal and 5 questions concerning suicidal ideation and feelings of guilt. The PTSD checklist is based on the DSM-IV criteria and has been validated as a screening tool for PTSD (Starr et al. 2004:1116). The scale uses specific referents like 'the injury' or 'my injury'. For example, most questions are symptom affirming and questions 3,4 or 5 are considered positive questions. Five questions $(19,21,24,25$ and 27$)$ are considered as symptom rejecting, whilst items 1, 2 and 3 are considered to be positive questions. This test has been validated by correlating the scores of victim reports about life threat or injury (Starr et al. 2004:1116). The scale has demonstrated good reliability and validity, with a Cronbach alpha coefficient of 0.86 (Starr et al. 2004:1116). A pilot study for this paper was conducted amongst a sample of 20 orthopaedic patients and found a good reliability and validity, with a Cronbach alpha coefficient of 0.85 .

Multidimensional Scale of Perceived Social Support (MSPSS, Zimet, Dahlem, Zimet \& Farley 1988): This tool uses a scale to evaluate the patient's perception of social support from family (FA), friends (FR) and significant others (SO). This scale was originally developed for university students and later validated on a wide range of samples (Cheng \& Chan 2004:1360). It has a total of 12 items; four questions are on family, four are about friends and another four inquires about support from significant others. The statements are rated on a 7-point Likert scale ( 1 = very strongly disagree; 7 = very strongly agree). Total MSPSS scores are calculated as the average of completed items, and higher scores indicated greater levels of perceived support. The validity of this scale was shown to be a good one with a coefficient alpha of 0.92 (Clapp \& Beck 2009:239). A study conducted amongst South African youth found that the MSPSS has a 0.86 Cronbach coefficient for the entire scale and coefficient ranging from $0.86-0.90$ for the subscales. Therefore this scale can be applied in South Africa (Bruwer et al. 2008:197).

General Health Questionnaire (GHQ-28, Goldberg \& Hillier 1979): This scale was used as a screening device to detect the prevalence of psychological strain within general medical practice (Kalliath, O'Driscoll \& Brough 2004:11). It is a self-report measure that has been widely used in studies of psychiatric morbidity around the world. The General Health Questionnaire (GHQ) has a 12, 28 and 60 item questionnaire. In this study, the 28 item version was used because it is easy to administer as it is simple and short (Quek et al. 2001:510). According to Leach (2006:9), a high score on the GHQ is indicative of a high level of psychological distress, whereas a low score indicates a low level of psychological distress. Isaksson and Johansson (2000, cited in Leach 2006:10) found Cronbach alpha coefficients of 0.86 for the total GHQ.

The GHQ-28 integrates four different subscales, which are (1) somatic symptoms, (2) anxiety and insomnia, (3) social dysfunction and (4) severe depression. Viljoen (2004, cited in Leach 2006:24) obtained a Cronbach alpha of 0.71 for the somatic symptoms subscale, 0.79 for the anxiety and insomnia subscale, 0.74 for the social dysfunction subscale and 0.80 for the depression subscale. The scale has been used and validated for South African samples (Idemudia \& Matamela 2012), thus making the GHQ instrument applicable in the South African context.

\section{Procedure}

After an Institutional Review Board of the North West University (Mafikeng Campus), the Provincial Department of Health (Gauteng) and the hospital approved the study. The study commenced by training research assistants that would help in data collection. They were trained in how to get participants' informed consent. Secondly, there was a one-day workshop where discussions were held about items on the questionnaire in Afrikaans and in Tswana so that research assistants could help non-English speakers. Thirdly, all ethical approvals from the three institutions were made available to the orthopaedic managers. Informed consent forms were obtained from those who were randomly selected. 
Non-English speakers were assisted by either Afrikaans or Tswana interpreters. The participants were first given the consent forms to sign, and then the questionnaires. For the purposes of confidentiality and anonymity, the participants were asked not to put their names on the questionnaires.

The participants were informed of their rights to withdraw from the study at any time if they wished. They were also informed that should they experience psychological distress, arrangements were in place for psychological intervention.

\section{Results}

In line with the first hypothesis, a correlation of social support and its subscales and mental health with subscales, and PTSD were computed (Table 1).

Table 1 shows that the subscales of the GHQ-28 measure were positively correlated with symptoms of PTSD (intrusion, avoidance, hyper-arousal, suicidal). Poor mental health showed a moderate to good relationship with symptoms of PTSD. There was a positive significant correlation between poor mental health and PTSD, $(r=0.52, n=200, p<0.05)$. There was a weak relationship between the multidimensional perceived social support subscale of significant others and avoidance $(r=-0.17)$. There was a fair degree of a negative relationship between family, friends and PTSD symptoms. There was a fair degree of a negative relationship between perceived social support and PTSD $(r=-0.27, n=200$, $p<0.05)$. According to Dawson and Trapp (2004), correlations can range from little or no relationship, 0 to $0.25(-0.25)$, a fair degree of relationship, 0.25 to $0.50(-0.25$ to -0.50$)$, to a moderate to good relationship 0.50 to 0.75 ( -0.50 to -0.75$)$.

Furthermore, there is a negative, statistically significant relationship between perceived social support and GHQ-28 $r=-0.17, n=200, p<0.05$. The family subscale was found to have a small, negative statistically significant relationship with the somatic and depression subscales. The friends subscale of the social support scale has a small, negative statistically significant relationship with all the subscales of the GHQ-28.
Hypothesis 2 was analysed with the multiple regression analysis (Table 2). Table 2 shows that the overall model is statistically significant, $R^{2}=0.28$, adjusted $R^{2}=0.26, \mathrm{~F}$ $(6196)=25.39$. The entire set of variables explains $28 \%$ of the total variance in PTSD. The t-test for PTSD $=8.70$ and the effect of PTSD total is statistically significant, meaning that the regression coefficient for PTSD is significantly different from zero. Perceived social support (MSPSS B $=0.07$ ) is not statistically significant $(p=0.66)$. Posttraumatic stress disorder (PTSD B $=0.28$ ) is statistically significant $(p=0.00)$ and is positively related, meaning that when PTSD increases there is an increase in poor mental health. Twenty-seven per cent of the variability of the GHQ-28 was accounted for by PTSD and MSPSS. The findings of this study refute the hypothesis that perceived social support will play a role or moderate mental health and PTSD amongst orthopaedic patients. The results of the study show that perceived social support did not moderate the relationship between PTSD and mental health.

\section{Discussion}

The objectives of this study were to investigate the relationship between mental health and PTSD after orthopaedic trauma and to empirically determine whether social support will moderate the relationship between mental health and PTSD. The results indicated that there is a significant relationship between mental health and PTSD after orthopaedic trauma, thereby confirming hypothesis 1 results also showed that social support did not moderate mental health and PTSD relationship and as a result hypothesis 2 was not confirmed. As predicted, there was a positive, statistically significant relationship between mental health and PTSD amongst orthopaedic patients. This finding supports the conceptualisation of the stress-buffering hypothesis. The theory implies that there is a relationship between mental health and PTSD following orthopaedic injuries and traumas. The findings of this study are in line with the study by Starr et al. (2004), which demonstrated that one in every two orthopaedic patients experience psychological distress. The findings indicate that orthopaedic patients do suffer from poor mental health, ranging from depression to somatic

TABLE 1: Means, standard deviations, and zero-order correlation.

\begin{tabular}{|c|c|c|c|c|c|c|c|c|c|c|c|c|c|c|c|c|}
\hline Variables & 1 & 2 & 3 & 4 & 5 & 6 & 7 & 8 & 9 & 10 & 11 & 12 & 13 & 14 & Mean & s.d. \\
\hline 1. Intrusion & & & & & & & & & & & & & & & 18.77 & 8.25 \\
\hline 2. Avoidance & & & & & & & & & & & & & & & 23.76 & 5.61 \\
\hline 3. Arousal & & & & & & & & & & & & & & & 18.55 & 5.51 \\
\hline 4. Suicidal & & & & & & & & & & & & & & & 11.45 & 4.13 \\
\hline 5. Somatic & 0.39 & 0.33 & 0.43 & 0.30 & 1 & & & & & & & & & & 1.77 & 2.19 \\
\hline 6. Anxiety & 0.45 & 0.34 & 0.47 & 0.37 & 0.88 & 1 & & & & & & & & & 2.16 & 2.31 \\
\hline 7. Social dysfunction & 0.46 & 0.39 & 0.51 & 0.36 & 0.88 & 0.91 & 1 & & & & & & & & 1.84 & 2.06 \\
\hline 8. Depression & 0.46 & 0.35 & 0.47 & 0.34 & 0.96 & 0.91 & 0.91 & 1 & & & & & & & 1.81 & 2.11 \\
\hline 9. Significant others & -0.08 & -0.17 & -0.11 & -0.09 & -0.09 & -0.08 & -0.10 & -0.10 & 1 & & & & & & 17.02 & 8.05 \\
\hline 10. Family & -0.14 & -0.25 & -0.21 & -0.2 & -0.15 & -0.11 & -0.12 & -0.14 & 0.48 & 1 & & & & & 18.35 & 6.51 \\
\hline 11. Friends & -0.19 & -0.3 & -0.23 & -0.26 & -0.19 & -0.16 & -0.15 & -0.18 & 0.34 & 0.51 & 1 & & & & 15.14 & 7.2 \\
\hline 12. PTSD T & 0.86 & 0.78 & 0.84 & 0.71 & 0.46 & 0.51 & 0.54 & 0.51 & -0.14 & -0.24 & -0.29 & 1 & & & 72.54 & 19.14 \\
\hline 13. MSPSS T & -0.17 & -0.30 & -0.23 & -0.22 & -0.18 & -0.15 & -0.16 & -0.18 & 0.79 & 0.81 & 0.77 & -0.27 & 1 & & 50.52 & 17.27 \\
\hline 14. GHQ-28 T & 0.46 & 0.36 & 0.49 & 0.35 & 0.96 & 0.96 & 0.95 & 0.98 & -0.09 & -0.13 & -0.18 & 0.52 & -0.17 & 1 & 7.59 & 8.4 \\
\hline
\end{tabular}

PTSD-T, Total Post Traumatic Stress Disorder; GHQ-28, General Health Questionnaire; MSPSS, Multidimensional Scale of Perceived Social Support; N, 200 
TABLE 2: Regression analyses and interaction effect for mental health and posttraumatic stress disorder by social support.

\begin{tabular}{|c|c|c|c|c|c|c|}
\hline \multirow[t]{2}{*}{ GHQ-28 Variables } & \multicolumn{2}{|c|}{ Overall } & \multicolumn{2}{|c|}{ Low MSPSS } & \multicolumn{2}{|c|}{ High MSPSS } \\
\hline & B & SE B & B & SE B & B & SE B \\
\hline PTSD_T & 0.28 & $0.07 * *$ & 0.26 & $0.04 * *$ & 0.19 & $0.03 * *$ \\
\hline MSPSS_T & 0.07 & 0.10 & - & - & - & - \\
\hline PTSD_T MSPSS_T & 0.00 & 0.00 & - & - & - & - \\
\hline$R^{2}$ & 0.28 & - & 0.28 & - & 0.24 & - \\
\hline$\Delta R^{2}$ & 0.26 & - & 0.27 & - & 0.23 & - \\
\hline$F^{*}$ & $25.39 * *$ & - & $38.70 * *$ & - & $31.11 * *$ & - \\
\hline $\begin{array}{l}\text { PTSD_T, Total scor } \\
\text { multidimensional } \\
\text { Questionnaire- } 28 ; \mathrm{B} \\
\text { Beta. } \\
{ }^{*} F \text {, a ratio of two } \mathrm{m} \\
{ }^{* *} p<0.05\end{array}$ & $\begin{array}{l}\text { for pos } \\
\text { e for } \\
\text { andardis } \\
\text { squares }\end{array}$ & $\begin{array}{l}\text { uma } \\
\text { ceiv } \\
\text { coefi }\end{array}$ & $\begin{array}{l}\text { ss disord } \\
\text { ial suppo } \\
\text { Beta; SE }\end{array}$ & $\begin{array}{l}\text { er; } \\
\text { ort; } \quad \mathrm{G} \\
\mathrm{B}, \text { Unst }\end{array}$ & $\begin{array}{l}\text { T, Total sc } \\
\text { 8; General } \\
\text { d error coe }\end{array}$ & $\begin{array}{l}\text { cores } f \\
\text { I Heal } \\
\text { ficient }\end{array}$ \\
\hline
\end{tabular}

symptoms and PTSD. It may seem that a broad range of disorders affect orthopaedic patients after a traumatic event. The current results replicate prior findings on the positive association between mental health and PTSD after injury (Lilly et al. 2009; Mayou et al. 2002; Ongecha-Owuor et al. 2004; Richmond et al. 2011; Rusch 1998;).

Theoretically, the stress-buffering hypothesis states that social support has an indirect and stress reducing effect by buffering the negative consequences of a traumatic event (Cohen \& Wills 1985:310). However, the findings in this study rejected the second hypothesis. Social support was found not to moderate the relationship between mental health and PTSD. A plausible reason could lie in the fact that whether or not social support is received, in African cultures, the man is the breadwinner and if he is unable to perform that role due to orthopaedic injuries, any social support given may be insignificant. A study conducted by Martz, Bodner and Livneh (2010) found that social support did moderate the perceived disability and posttraumatic stress levels amongst Vietnam theatre veterans. It is also possible that people may receive social support and not be satisfied with it. Unfortunately, this study did not investigate levels of satisfaction with the social support received.

Orthopaedic patients need a holistic intervention, which includes treatment of their injuries, psychological interventions, and social support.

\section{Conclusion}

From this study, the following conclusions are made:

- There is a significant relationship between mental health and PTSD of orthopaedic patients

- Social support received did not moderate the relationship between mental health and PTSD.

\section{Recommendations}

The findings of this study must be interpreted with caution; the generalisability of the findings obtained is limited. This is because the collection of data was limited to one hospital. The other limitation is that the study did not determine whether the participants had pre-existing mental health problems.
The findings of this study have implications for the need for psychological services in general hospitals, where patients should be holistically treated rather than undergoing the part-treatment currently being given.

The recommendation is that further studies be encouraged with pre- and post-screening of mental health and that many hospitals be involved in such studies. Structured clinical interviews may be better able to differentiate between comorbid physical illnesses and symptoms of depression and PTSD.

Health workers should be trained on the symptomology of PTSD and poor mental health amongst orthopaedic patients. Every orthopaedic patient should be attended to by a psychologist. Health workers such as doctors and nurses should work with psychologists and counsellors in helping orthopaedic patients. In fact, clinical psychologists should, as matter of policy, work in orthopaedic units to enable them assess and treat patients with likely psychological problems.

\section{Limitations}

The study used a single setting (hospital) in a single province. Sample size was also small. Future research should address the limitations identified in this study.

\section{Acknowledgements}

The authors wish to acknowledge the cooperation of the participants despite their pain and sufferings in the hospital. Thank you for contributing to knowledge in South Africa.

\section{Competing Interests}

The authors have no financial disclosures or conflicts of interest to report.

\section{Authors' contributions}

V.M. (North West University) was primarily responsible for data collection including entry, cleaning, data analysis, drafting and. E.S.I. (North West University) conceptualised the study and was involved in project planning, the revision of all drafts and correction of the manuscript.

\section{References}

American Psychiatric Association, 2000, Desk reference to the diagnostic criteria from $D S M-I V-T R$, 4th edn., American Psychiatric Publishing, Arlington, VA.

Bal,S., Crombez, G., Van Oost, P. \& Debourdeaudhuij, I., 2003, 'The role of social support in the well-being and coping with self-reported stressful events in adolescents', Child Abuse \& Neglect 27, 1377-1395. http://dx.doi.org/10.1016/j. chiabu.2003.06.002, PMid:14644056

Blanchard, E.B. \& Hickling, E.J., 1997, After the crash: Assessment and treatment of motor vehicle accident survivors. American Psychological Association, Washington. http://dx.doi.org/10.1037/10237-000

Bruwer, B., Emsley, R., Kidd, M., Lochner, C. \& Seedat, S., 2008, 'Psychometric properties of the multidimensional scale of perceived social support in youth', Comprehensive Psychiatry 49, 195-201. http://dx.doi.org/10.1016/j. comppsych.2007.09.002, PMid:18243894

Cheng, S. \& Chan, A.C.M., 2004, 'The multidimensional scale of perceived social support: Dimensionality and age and gender differences in adolescents', support: Dimensionality and age and gender differences in adolescents',
Personality and Individual Differences 37, 1359-1369. http://dx.doi.org/10.1016/j. paid.2004.01.006 
Chossegros, L., Hours, M., Charnay, P., Bernard, M., Fort, E., Boisson, D. et al., 2011, Predictive factors of chronic post-traumatic stress disorder 6 months after a road traffic accident. Accident Analysis and Prevention 43, 471-477. http://dx.doi. traffic accident. Accident Analysis and Prevention
org/10.1016/j.aap.2010.10.004, PMid:21094346

Clapp, J.D. \& Beck, J.G., 2009, 'Understanding the relationship between PTSD and social support: The role of negative network orientation', Behaviour Research and Therapy 47, 237-244. http://dx.doi.org/10.1016/j.brat.2008.12.006, PMid:19162260, PMCid:2656396

Clay, F.J., Newstead, S.V. \& McClure, R.J., 2010, 'A systematic review of early prognostic factors for return to work following acute orthopaedic trauma', International Journal of Care Injured 4, 787-803.

Cohen, S. \& Wills, T.A., 1985, 'Stress, social support, and the buffering hypothesis', Psychological Bulletin 98, 310-357. http://dx.doi.org/10.1037/0033-2909.98.2.310, PMid:3901065

Coronas, R., Garcia-Pares, G., Viladrich, C., Santos, J.M. \& Menchon, J.M., 2008 'Clinical and Socio-demographic variables associated with the onset of posttraumatic stress disorder in road traffic accidents', Depression and Anxiety 25 E16-E23. http://dx.doi.org/10.1002/da.20324, PMid:17607753

Corrigall, J., Ward, C., Stinson, K., Struthers, P., Frantz, J., Lund, et al., 2007, 'Decreasing the burden of mental illness', Western Cape Burden of Disease Reduction Project $4,21-26$.

Dawson, B. \& Trapp, R.G., 2004, Basic and clinical biostatistics, 4th edn., Lange Medical Books/McGraw-Hill, New York.

Ehlers, A., Mayou, R.A. \& Bryant, B., 1998, 'Psychological predictors of chronic posttraumatic stress disorder after motor vehicle accidents', Journal of Abnormal Psychology 107, 508-519. http://dx.doi.org/10.1037/0021-843X.107.3.508, Psychology 107

Elwood, L.S., Hahn, K.S., Olatunji, B.O. \& Williams, N.L., 2009, 'Cognitive vulnerabilities to the development of PTSD: A review of four vulnerabilities and the proposal of an integrative vulnerability model', Clinical Psychology Review 1, 87-100. http:// dx.doi.org/10.1016/j.cpr.2008.10.002, PMid:19008028

Forbes, D., Creamer, M. \& Biddle, D., 2001, 'The validity of the PTSD checklist as a measure of symptomatic change in combat-related PTSD', Behavior Therapy and Research 39, 977-986. http://dx.doi.org/10.1016/S0005-7967(00)00084-X

Girolami, A., Foex, B.A. \& Little, R.A., 1999, 'Changes in the causes of trauma in the last 20 years', Trauma 1, 3-11. http://dx.doi.org/10.1177/146040869900100101

Goldberg, D.P. \& Hillier, V.F., 1979, 'A scaled version of the General Health Questionnaire', Psychological Medicine 9, 139-145. http://dx.doi.org/10.1017/ S0033291700021644, PMid:424481

Green, M.M., McFarlane, A.C., Hunter, C.E. \& Griggs, W.M., 1993, 'Undiagnosed posttraumatic stress disorder following motor vehicle accidents', Medical Journal of Australia 159, 529-534. PMid:8412952

Holbrook, T. L., Anderson, J.P., Sieber, W.J., Browner, D. \& Hoyt, D.B., 1998, 'Outcome after major trauma: Discharge and 6-month follow-up results from the trauma recovery project', Journal of Trauma-Injury Infection \& Critical Care 45(2), 315recovery project', Journal of Trauma-Injury Infection \& Critical
324. http://dx.doi.org/10.1097/00005373-199808000-00018

Ibarra-Rovillard, M.S. \& Kuiper, N.A., 2011, 'Social support and social negativity findings in depression: Perceived responsiveness to basic psychological needs', Clinical Psychology Review 31(3), 342-352. http://dx.doi.org/10.1016/j. Clinical Psychology Review $31(3)$
cpr.2011.01.005, PMid:21382539

Idemudia, E.S. \& Matamela, N.A., 2012. 'The role of stigmas in mental health: A comparative study', Curationis, 35(1). http://dx.doi.org/10.4102/curationis. v35i1.30

Jones, L., Hughes, M., Unterstaller, U., 2001, 'Post-traumatic stress disorder (PTSD) in victims of domestic violence: A review of the research', Trauma Violence \& Abuse 2, 99-119. http://dx.doi.org/10.1177/1524838001002002001

Kalliath, T.J., O'Driscoll, M.P. \& Brough, P., 2004, 'A confirmatory factor analysis of the General Health Questionnaire-12', Stress and Health 20(1), 11-20. http://dx.doi. org/10.1002/smi.993

Latchford, G., 2003, 'Accident and trauma', in P. Kennedy \& S. Llewelyn (eds.), The essentials of clinical health psychology. Wiley, Hoboken, NJ.

Laumon, B., 2011, 'Predictive factors of chronic post-traumatic stress disorder 6 months after a road traffic accident', Accident Analysis and Prevention 43, 471477. http://dx.doi.org/10.1016/j.aap.2010.10.004, PMid:21094346

Leach, R.J., 2006, 'Job insecurity, resilience and general health of motor-trade employees', MA thesis, Department of Industrial Psychology, North-West University, Vaal Triangle Campus.

Lilly, M.M., Pole, N., Best, S.R., Metzler, T. \& Marmar, C.R., 2009, 'Gender and PTSD: What can we learn from female police officers?' Journal of Anxiety Disorders 23, 767-774. http:
Martz, E., Bodner, T. \& Livneh, H., 2010, 'Social support and coping as moderators of perceived disability and posttraumatic stress levels among Vietnam theatre veterans', Health 2(4), 332-341. http://dx.doi.org/10.4236/ health.2010.24050Mayou, R., Bryant, B. \& Duthie, R., 1993, 'Psychiatric health.2010.240 http://dx.doi.org/10.1136/bmj.307.6905.647m PMid:8401049, PMCid:1678958

Mayou, R.A., Ehlers, A. \& Bryant, B., 2002, 'Posttraumatic stress disorder after motor vehicle accidents: 3-year follow-up of a prospective longitudinal study', Behaviour
Research and Therapy 40(6), 665-675. http://dx.doi.org/10.1016/S00057967(01)00069-9

Najavits, L.M., Sonn, J.,Walsh, M. \& Weiss, R.D., 2004, Domestic violence in women with PTSD and substance abuse. Addictive Behaviours 29, 707-715. http://dx.doi. org/10.1016/j.addbeh.2004.01.003, PMid:15135552

Norris, F.H. \& Perilla, J.L., 1996, 'The Revised Civilian Mississippi Scale for PTSD: Reliability, validity, and cross-language stability', Journal of Traumatic Stress 9(2), 285-298. http://dx.doi.org/10.1002/jts.2490090210, PMid:8731548

Ongecha-Owuor, F.A., Kathuku, D.M., Othieno, C.J. \& Ndetei, D.M., 2004, 'Post traumatic stress disorder among motor vehicle accident survivors attending the orthopaedic and trauma clinic at Kenyatta national hospital, Nairobi', East African Medical Journal 81(7), 362-366. http://dx.doi.org/10.4314/eamj.v81i7.9192, PMid:15490709

Ponsford, J., Hill, B., Phys, D., Karamitsios, M. \& Bahar-Fuchs, A., 2008, 'Factors influencing outcome after orthopaedic trauma', The Journal of Trauma Injury Infection and Critical Care 64(4), 1001-1009. http://dx.doi.org/10.1097/ TA.0b013e31809fec16, PMid:18404068

Pruitt, L.D. \& Zoellner, L.A., 2008, 'The impact of social support: An analogue investigation of the aftermath of trauma exposure', Journal of Anxiety Disorders 22(2), 253-262. http://dx.doi.org/10.1016/j.janxdis.2007.02.005, PMid:17368829

Quek, K.F., Low, W.Y., Razack, A.H. \& Loh, C.S., 2001, 'Reliability and validity of the General Health Questionnaire (GHQ-12) among urological patients: A Malaysian study', Psychiatry and Clinical Neuroscience 55, 509-513. http://dx.doi. org/10.1046/j.1440-1819.2001.00897.x, PMid:11555347

Rees, T., Mitchell, I., Evans, L., Hardy, L., 2010, 'Stressors, social support and psychological responses to sport injury in high- and low-performance standard participants', Psychology of Sport and Exercise 11(6), 505-512. http://dx.doi. org/10.1016/j.psychsport.2010.07.002

Richmond, T.S., Ruzek, J., Ackerson, T., Wiebe, D.J., Winston, F. \& Kassam-Adams, N., 2011, 'Predicting the future development of depression or PTSD after injury', General Hospital Psychiatry 33, 327-335. http://dx.doi.org/10.1016/j. genhosppsych.2011.05.003, PMid:21762828, PMCid:3139106

Rusch, M.D., 1998, 'Psychological response to trauma', Plastic Surgical Nursing 18(3), 147-158. PMid:10205518

Starr, A.J., Smith, W.R., Frawley, W.H., Borer, D.S., Morgan, S.J., Reinert, C.M. et al., 2004, 'Symptoms of posttraumatic stress disorder after orthopaedic trauma', The Journal of Bone and Joint Surgery 86(6), 1115-1121. PMid:15173282

Steel, J.L., Dunlavy, A.C., Stillman, J. \& Pape, H.C., 2011, 'Measuring depression and PTSD after trauma: Common scales and checklists', International Journal of Care PTSD after trauma: Com
Injured 42, 288-300.

Strydom, H., 2005, 'Ethical aspects of research in the social sciences and human service professions', in A.S. de Vos, H. Strydom, C.B. Fouche, \& C.S.L. Delport (eds.), Research at grass roots: For the social sciences and human service professions, $\mathrm{p}$ 56-70, Van Schaik, Pretoria.

Tajalli, P., Sobhi, A. \& Ganbaripanah, A., 2010, 'The relationship between daily hassles and social support on mental health university students', Procedia Social and Behavioural Sciences 5, 99103. http://dx.doi.org/10.1016/j.sbspro.2010.07.058

WHO is used for World Health Organization

WHO, 2009, World health report 2009: Global status report on road safety. World Health Oganization, Geneva.

Wong, E.C., Kennedy, D., Marshall, G.N. \& Gaillot, S., 2011, 'Making sense of posttraumatic stress disorder: Illness perceptions among traumatic injury survivors', Psychological Trauma: Theory, Research, Practice and Policy 3(1), 6776. http://dx.doi.org/10.1037/a0020587

Yehuda, R., 2002, 'Post-traumatic stress disorder', The New England Journal of Medicine 346(2), 108-114. http://dx.doi.org/10.1056/NEJMra012941, PMid:11784878

Yehuda, R., McFarlane, A.C., \& Shalev, A.Y., 1998, 'Predicting the development of posttraumatic stress disorder from acute response to a traumatic event', Society posttraumatic stress disorder from acute response to a traumatic event', Society
of Biological Psychiatry 44, 1305-1313. http://dx.doi.org/10.1016/S0006of Biological Psych

Zimet, G.D., Dahlem, N.W., Zimet, S.G. \& Farley, G.K., 1988, 'The multidimensional scale of perceived social support', Journal of Personality Assessment 52, 30-41. http://dx.doi.org/10.1207/s15327752jpa5201_2 